\title{
Prevalence, risk factors and antibiogram of Esch- erichia coli isolated from dogs in Ambo, Gojo and Bako towns of Oromia region, Ethiopia
}

\author{
Endrias Zewdu Gebremedhin ${ }^{1^{*}}$ Demiso Merga ${ }^{2}$, Edilu Jorga Sarba ${ }^{1}$, Lencho Megersa \\ Marami ${ }^{3}$, Getachew Kebebew Tola ${ }^{1}$ and Solomon Shiferaw Endale ${ }^{3}$ \\ ${ }^{1}$ Department of Veterinary Sciences, School of Veterinary Medicine, Ambo University, P.O. Box 19, \\ Ambo, Ethiopia \\ ${ }^{2}$ School of Veterinary Medicine, Wollega University, P.O. Box 395, Nekemte,Ethiopia \\ ${ }^{3}$ Department of Veterinary Laboratory Technology, School of Veterinary Medicine, Ambo Univer- \\ sity, P.O. Box 19, Ambo, Ethiopia \\ ${ }^{*}$ Corresponding author: Prof. Endrias Zewdu:endrias.zewdu@gmail.com
}

\begin{abstract}
Dogs are a potential reservoir for Escherichia coli and other zoonotic bacterial pathogens posing the risk of infection to humans and other animals. A crosssectional study was used to collect 438 rectal swab samples from apparently healthy dogs of Ambo, Gojo, and Bako towns of West Shewa Zone with the objectives of investigating the prevalence, risk factors and antibiogram of $E$. coli. A questionnaire survey was administered at the household level to collect data on potential risk factors to acquire $E$. coli infection. Prevalence was determined by using standard bacteriological culture techniques. Further confirmation and antimicrobial susceptibility testing of $E$. coli using the minimum inhibitory concentration (MIC) method were conducted using Automated Phoenix Machine. The overall prevalence of $E$. coli was found to be $24.2 \%$ (95\% confidence interval [CI]:20.26-28.49\%). The isolation rate of $E$. coli was the highest in Bako $31.01 \%$, followed by Gojo 30.99\% and Ambo 18.49\% towns. Univariable and multivariable logistic regression analyses revealed that there was a significant association between $E$. coli prevalence and towns and Kebeles $(P<0.05)$. However, age, sex, the presence of other domestic animals in the household, types of the housing system, educational level of the dogs' owners, and type of feed provided to the dogs did not significantly correlate with the isolation of $E$. coli $(P>0.05)$. E. coli isolates were pan-susceptible to amikacin, ertapenem, imipenem, piperacillin-tazobactam, netilmicin, ampicillin, piperacillin, cefoxitin, ciprofloxacin, levofloxacin, and meropenem. A low level of resistance was found to aztreonam, ceftriaxone, (each $13.95 \%$ ), cefazolin $(22.73 \%)$, gentamicin (11.90\%), and trimethoprim-sulphamethoxazole (6.97\%). E. coli isolates
\end{abstract}


showed multidrug resistance to aztreonam, cefazolin, ceftriaxone, gentamicin, and trimethoprim-sulphamethoxazole (14.0\%). This demonstrated E. coli prevalence and moderately low antimicrobial resistance suggests the possible risk of infection of humans. Therefore, raising public awareness about zoonotic canine disease prevention measures and good hygienic practices are essential..

Keywords: Antibiogram, Dog, Escherichia coli, Ethiopia, Prevalence, Risk factor.

\section{Introduction}

Dogs benefit humankind in several ways such as through guiding blind people, guarding, and hunting (Dantas-Torres and Otranto, 2014). The ownership of a dog has been associated with a decreased likelihood of high blood pressure, obesity, and cardiovascular disease (McConnell et al., 2011). However, there are several health hazards associated with owning dogs (Damborg et al., 2009) such as viral, bacterial, protozoal, and helminth infections; and bite and allergy. Considering the large number of people sharing their homes with dogs and the close relationship that many owners share with their dogs, the public health impacts of dogs as companion animals is important to consider, particularly with the One Health initiatives which aim to integrate human, animal and environmental health (Blaha, 2012).

Escherichia coli normally reside in the lower intestines of most warm-blooded mammals, including dogs. Normally, the presence of $E$. coli is benign and even beneficial, but in some cases, it can cause disease, especially in newborn puppies and in those with impaired local or systemic immunity (Beutin, 1999). The enteric $E$. coli are divided based on virulence properties into Enterotoxigenic (ETEC), Enteropathogenic (EPEC), Enteroinvasive (EIEC), Verotoxigenic (VTEC), Enterohemorrhagic (EHEC) and Enteroaggregative (EaggEC) (Frenzen and Drake, 2005).

The pathogenic strains or clones of $E$. coli which exist in canines are capable of causing significant morbidity and mortality in humans as well as in pets (Sanyal et al., 1997; Beutin, 1999; Sancak et al., 2004). Besides its role in gastrointestinal infections, $E$. coli can cause infections of the urogenital tract and systemic disease in dogs and cats (Beutin, 1999). Moreover, companion animals are of importance in global antimicrobial resistance research, particularly due to the consistent intimate contact they have with humans, and thus their pu- 
tative role in the transmission of zoonotic resistant bacteria like $E$. coli, either directly or indirectly through contact and the environment (Guardabassi et al., 2004; Ewers et al., 2012).

It has been reported that canine feces represent a potential reservoir for the human acquisition of commensal bacteria, such as $E$. coli, that can act as a major source of antimicrobial resistance genes (Caprioli et al., 2000). E. coli have been extensively studied in farm animals as well as pets around the world (PuñoSarmiento et al., 2013). In Ethiopia, the presence of $E$. coli in general and $E$. coli O157: H7, in particular, have been studied in meat/carcass of ruminants (Hiko et al., 2008; Mersha et al., 2010; Taye et al., 2013; Bekele et al., 2014; Dulo et al., 2015; Abdissa et al., 2017; Atnafie et al., 2017; Beyi et al., 2017), bovine milk (Bihon et al., 2018), in yogurt and cheese/cottage cheese (Tsegaye and Ashenafi, 2005), fruit juice (Mutaku et al., 2005), in feces and skin (Mersha et al., 2010), urine of pregnant women (Gessesse et al., 2017). But, to the best of the author's knowledge, no published information is available regarding the epidemiology, antibiogram, and potential public health risks of $E$. coli in dogs. Thus, this study was conducted to estimate the prevalence of $E$. coli from rectal swabs of dogs, to assess the potential risk factors of infection and to determine the antibiogram of E. coli isolates in Ambo, Gojo and Bako towns of West Shewa Zone, Oromia region, Ethiopia.

\section{Materials and methods}

\section{Study area}

The study was conducted in three selected towns, namely Ambo, Bako, and Gojo, located in Oromia Region, West Shewa Zone. Ambo town is the administrative center of the Zone of West Shewa located $114 \mathrm{~km}$ west of Addis Ababa, the capital of Ethiopia, between latitudes of $8^{\circ} 59^{\prime} \mathrm{N}-8.983^{\circ} \mathrm{N}$ and longitudes of $37^{\circ} 51^{\prime} \mathrm{E}-37.85^{\circ} \mathrm{E}$. The elevation of the town ranges from 1900 to 2275 meters above sea level (masl). Its temperature ranges from $19^{\circ} \mathrm{C}$ to $29^{\circ} \mathrm{C}$ with an average annual temperature of $22^{\circ} \mathrm{C}$ and an average annual rainfall of about 900 $\mathrm{mm}$. The town has a total human population of 74, 843 out of which 39,192 are males, and 35,651 are females (CSA, 2005).

Bako town, the administrative center of Bakotibe district, is located $260 \mathrm{Km}$ West of Addis Ababa and lies between $9.1274^{\circ} \mathrm{N}$ and $37.0561^{\circ} \mathrm{E}$. The elevation of the town ranges from 960 to 2450 masl. The mean annual rainfall is 886.5 
$\mathrm{mm}$. The monthly mean temperature of the town varies from $14.5^{\circ} \mathrm{C}$ in December to $21.6^{\circ} \mathrm{C}$ in June with an average annual temperature of $28^{\circ} \mathrm{C}(\mathrm{BTAC}$ and Agricultural Bureau, 1998). The town has a total human population of 35,769 out of which 16,692 are male and 19,077 are females (CSA, 2005).

Likewise, Gojo town is the administrative center of Jeldu district of West Shoa Zone located $120 \mathrm{Km}$ West of Addis Ababa, between 9.2659 ${ }^{\circ} \mathrm{N}$ and $38.0817^{\circ} \mathrm{E}$. The elevation of the town ranges from 1800 to 2550 masl. The mean temperature of the town is $20^{\circ} \mathrm{C}$ and gains an annual average rainfall of $2500 \mathrm{~mm}$. The human population of Jeldu district is 202,655 of which 102,796 are females and the remaining 99,859 males (CSA, 2008). The three towns have bimodal rainfall characterized by a small rainy season from February to May and a big rainy season from July to September. The dry season extends from October to January (CSA, 2007; CSA, 2015). There was no accessible recorded statistical information on the dog population in the three study towns.

\section{Study populations and study animals}

Study populations were dogs including local, exotic and crossbreeds owned by the households in the three selected towns of West Shewa zones. The study animals are dogs in the selected Gotes (a sub Kebele holding up to 50 households) and Kebeles (smallest administrative unit of a district/town) in the three towns.

\section{Study design}

A cross-sectional survey was used to study the prevalence, risk factors, and antibiogram of $E$. coli from rectal swab samples of dogs.

\section{Sample size determination}

The sample size was determined according to Thrusfield's (2005) formula with an expected prevalence of $50 \%, 5 \%$ desired absolute precision and $95 \%$ confidence interval since there is no previous study conducted on $E$. coli of dogs in Ethiopia.

\section{$\mathrm{N}=1.962 \operatorname{Pexp}(1-\mathrm{Pexp}) / \mathrm{d} 2$}

Where $n=$ required sample size, $\mathrm{p}=$ expected prevalence $\mathrm{d}=$ desired absolute precision. Therefore, the calculated sample size was 384 . For better precision, 
438 animals were investigated. There was no data on the dog population in the three towns. The distribution of the dog population in each Kebeles of the study towns was assumed uniform. There are three Kebeles in Ambo town while Bako and Gojo towns have two and one Kebeles respectively. The total sample size was allocated to Ambo $(n=238)$, Bako $(n=129)$, and Gojo $(n=71)$ towns roughly proportional to the human population.

\section{Study methodology}

\section{Questionnaire survey}

A semi-structured pretested questionnaire was administered to dog owners during sample collection. Questions asked to dog owners include dog management, housing system, feeding, presence of other animals in the household, veterinary care, and educational level of the owners.

Data collection format was also prepared and used to record the sex (female, male), age (juvenile ( 6 weeks to 6 months), adolescent ( 7 months to 18 months), adult (19 months to 7 years), geriatric (greater than 7 years) (Kiflu et al., 2017)), breed (local, exotic \& cross), district (Ambo, Bako, Gojo), housing (indoor, outdoor, mixed), feeding (household leftover, raw animal products, cooked animal products, mixed), of the all sampled dogs.

\section{Sample collection and transportation}

From each "Kebeles," four "Gotes" were randomly selected using the list of Gotes in each Kebeles (sampling frame) provided by local administrators. The index household in a Gote was randomly selected and subsequent households were surveyed door to door. Before the fecal swab samples collection, $70 \%$ ethyl alcohol impregnated cotton was used to clean the perianal area of each dog. Prior to sample collection, restraining of dogs was performed manually using movable metallic crush. The sterile cotton-tipped applicator stick was inserted $2-4 \mathrm{~cm}$ into the rectum, slightly rotated to collect fecal material, then gently removed, put into peptone water, and immediately transported to Ambo University Zoonoses and Food Safety Laboratory using an icebox with ice packs. In the laboratory, the samples were processed immediately, otherwise stored at $4^{\circ} \mathrm{C}$ until examined in 2 days. 


\section{Isolation of Escherichia coli}

The swab samples were incubated overnight in buffered peptone water at $37^{\circ} \mathrm{C}$ for 24 hours. Then, a loopful of bacteria from peptone water was cultured on MacConkey agar (BM020, Sisco Research Laboratories Pvt. Ltd., India) for 18 to 24 hours at $37^{\circ} \mathrm{C}$. Typical lactose fermenting pink color colony was picked and streaked again on Eosin Methylene Blue (EMB) agar (BM020, Sisco Research Laboratories Pvt. Ltd, India). Green metallic sheen isolates were considered to be $E$. coli and the presumptive colonies were transferred on nutrient agar. Then, isolates were biochemically tested using the IMVIC (indole, methyl red, Voges Proskauer, and citrate) test and on triple sugar iron agar (TSI) and motility. The $E$. coli isolates revealed a complete fermentation of 5 basic sugars by producing both acid and gas. The isolates were also revealed a positive reaction to the MR test and the Indole test but a negative reaction to the VP test. TSI agar medium gave yellow color in both the slant and butt with gas production.

\section{Identification and antimicrobial susceptibility test}

Further Identification (ID) and antimicrobial susceptibility test (AST) were performed at the International clinical laboratory (ICL) located in Addis Ababa, Ethiopia. Fifty-seven isolates of $E$. coli identified by biochemical tests were transported to ICL using a cold chain. Then, isolates were sub-cultured on MacConkey agar media and incubated for 24 hours. After all bacterial colonies and materials were collected to the inoculation site, Phoenix ID broth was labeled. Using an aseptic technique, fresh colonies of the same morphology were picked up with the tip of a sterile cotton swab and suspended in the phoenix ID broth $(4.5 \mathrm{ml})$ then the tube was capped tightly, vortexed for five seconds and allowed to settle for approximately ten seconds for air bubbles to surface. After this, the tube was inserted into the BD Phoenix Spec ${ }^{\mathrm{TM}}$ nephelometer to measure inoculum density which was set to $0.5 \mathrm{McF}$ arland for the panel type being run (range of 0.5-0.6 is acceptable). The density of the organism was adjusted by either adding colonies from the isolate or diluting the broth with fresh Phoenix ID broth and re-measuring the turbidity. Then, the Phoenix AST broth tube $(8 \mathrm{ml})$ was labeled with the sample code and one free-falling drop of AST Indicator solution was added to it and was inverted to mix. Then, $25 \mu \mathrm{L}$ of the bacterial suspension from the ID broth tube was transferred into the AST broth tube using a sterile pipette. Then, the AST tube was capped and inverted several times to be mixed. After waiting for few seconds for air bubbles, 
ID tube inoculum was poured into the fill port on the ID side of the panel (Gram-negative tray with E. coli ATCC 25922 used as quality control organism) and the fluid was allowed to traverse down the tracks. Then, AST broth inoculums were poured into the fill port on the AST side of the panel (85 well sides) and the fluid was allowed to traverse down the tracks before moving the panel. Then the panel closure was snapped on and the panels were inserted in the transportation caddy. Before insertion of the panel into the Phoenix 100 machine, all panels were logged into the panel log in soft key. After the panel soft key was opened, all information was fed into the software and saved. The panels were inserted into the BD Phoenix 100 machine. The load panel key on the instrument was pressed to hear the audible signal sounds, then, the door unlocked icon appeared and the instrument door was opened and the panel holder where there was no panel in place was selected. Then, the bottom part of the panel was placed in the panel holder and pressed downward; the top of the panel was pivoted back into the panel holder and then allowed to move upward. Lastly, the instrument door was closed.

The antimicrobials for testing drug resistance were selected based on information obtained from local health authorities (personal communication) about the antibiotics that are used to treat human and animal E. coli infections in Ethiopia. E. coli isolates resistant to three or more classes of antimicrobials were considered to be multidrug-resistant (MDR) (Magiorakos et al., 2012). The Minimal Inhibitory Concentration (MIC) Interpretive Standards were shown in Table 1. 
Table 1. Minimal Inhibitory Concentration (MIC) Interpretive Standards for Enterobacteriaceae

\begin{tabular}{|c|c|c|c|}
\hline \multirow[t]{2}{*}{ Antimicrobial agents } & \multicolumn{3}{|c|}{ Minimum Inhibition Concentration (MIC) } \\
\hline & $\begin{array}{l}\text { Susceptible at }<\mu \mathrm{g} / \\
\mathrm{ml}\end{array}$ & Intermediate & $\begin{array}{l}\text { Resistance at } \geq \mu \mathrm{g} / \\
\mathrm{ml}\end{array}$ \\
\hline Amikacin & 16 & 32 & 64 \\
\hline Amoxicillin-Clavulanate & $8 / 4$ & $16 / 8$ & $32 / 16$ \\
\hline Ampicillin & 8 & 16 & 32 \\
\hline Ampicillin-Sulbactam & $8 / 4$ & $16 / 8$ & $32 / 16$ \\
\hline Aztreonam & 4 & 8 & 16 \\
\hline Cefazolin & 2 & 4 & 8 \\
\hline Cefepime & 2 & - & 16 \\
\hline Cefoxitin & 8 & 16 & 32 \\
\hline Ceftazidime & 4 & 8 & 16 \\
\hline Ceftriaxone & 1 & 2 & 4 \\
\hline Cefuroxime & 8 & 16 & 32 \\
\hline Ciprofloxacin & 0.06 & $0.12-0.5$ & 1 \\
\hline Ertapenem & 0.5 & 1 & 2 \\
\hline Gentamicin & 4 & 8 & 16 \\
\hline Imipenem & 1 & 2 & 4 \\
\hline Levofloxacin & 2 & 4 & 8 \\
\hline Meropenem & 1 & 2 & 4 \\
\hline Netilmicin & 8 & 16 & 32 \\
\hline Piperacillin & 16 & $32-64$ & 128 \\
\hline Piperacillin-Tazobactam & $16 / 2$ & $32 / 4-64 / 4$ & $128 / 4$ \\
\hline Ticarcillin & 16 & $32-64$ & 128 \\
\hline Ticarcillin clavulanate & $16 / 4$ & $32 / 2-64 / 2$ & $128 / 2$ \\
\hline Tigecycline & - & 2 & 8 \\
\hline $\begin{array}{l}\text { Trimethoprim- } \\
\text { Sulphamethoxazole }\end{array}$ & $2 / 38$ & - & $4 / 72$ \\
\hline
\end{tabular}

Source: CLSI, 2015

\section{Data management and analysis}

All data collected from the questionnaire survey and laboratory analysis were entered into the Microsoft-Excel spreadsheet. Descriptive statistics were used to summarize the data. STATA version 14.0 software (Stata Corp. College Station, USA) was used to analyze the data. The association between the prevalence of $E$. coli infection in dogs and potential risk factors was first analyzed using a Chi-square test followed by univariable and multivariable logistic regression analyses.The association of the explanatory variables was first tested using univariable logistic regression. Non-collinear variables with $P$ - 
value $<0.25$ in univariable analyses were entered into a multivariable logistic regression model. The interaction of variables that remained in the full model was carried out. A likelihood ratio test with a $P$-value of less than 0.05 suggested an interaction between the two variables being tested and was retained in the final model. In all the analyses $P$-value of less than 0.05 was considered significant.

\section{Results}

\section{Prevalence}

A total of 106 of 438 (24.2\%, 95\% confidence interval [CI]: 20.26-28.49\%) dogs tested positive for $E$. coli. The Chi-square test showed that there was a significant difference in prevalence among the study towns $(P<0.05)$ (Table 2,3$)$.

Table 2. Prevalence of $E$. coli in dogs of Ambo, Bako, and Gojo towns of West Shewa Zone, Oromia, Ethiopia

\begin{tabular}{|c|c|c|c|c|}
\hline $\begin{array}{l}\text { Study } \\
\text { area/ } \\
\text { towns }\end{array}$ & $\begin{array}{l}\text { No. of samples } \\
\text { tested }\end{array}$ & No. positive & $\begin{array}{l}\text { Prevalence } \\
(\%)\end{array}$ & $95 \% \mathrm{CI}$ \\
\hline Ambo & 238 & 44 & 18.49 & $13.77-24.01$ \\
\hline Bako & 129 & 40 & 31.01 & $23.16-39.75$ \\
\hline Gojo & 71 & 22 & 30.99 & 20.54-43.08 \\
\hline Total & 438 & 106 & 24.20 & $20.26-28.49$ \\
\hline
\end{tabular}

\section{Risk Factors}

Univariable logistic regression analysis revealed a significant association between the $E$. coli prevalence and district towns. The odds of the $E$. coli prevalence from Bako town was 1.98 (95\% CI: 1.21-3.26, $P=0.007)$ times higher than for dogs at the Ambo town. Similarly, the odds of the E. coli prevalence from the Gojo town was 1.98 (95\% CI: 1.09 - 3.61, $P=0.026$ ) times higher than that of Ambo town. There was a significant difference in the prevalence of $E$. coli among sampled Kebeles. Univariable logistic regression revealed that the odds of E. coli infection in Kebele 03 of Ambo town was 38.77 (95\% CI: 5.11-294.10: $P \leq 0.001)$ times higher than that of Ambo 01 Kebele. The univariable analysis also showed that there was no significant association $(P>0.05)$ between $E$. coli prevalence and age, sex, breed, presence of other domestic animals in the home, education of the owner, the gender of the owner and visiting veterinary clinics (Table 3). 
Zewdu et al.,

Table 3. Results of univariable logistic regression analyses of E. coli carriage and its association with the putative risk factors in dogs of Ambo, Bako, and Gojo towns

\begin{tabular}{|c|c|c|c|c|c|}
\hline Variables & Categories & $\begin{array}{l}\text { No. } \\
\text { tested }\end{array}$ & $\begin{array}{l}\text { No. positive } \\
(\%)\end{array}$ & OR (95\% CI) & p-value \\
\hline \multirow[t]{3}{*}{ Districts/ towns } & Ambo & 238 & $44(18.49)$ & 1.00 & \\
\hline & Bako & 129 & $40(31.01)$ & $1.98(1.09-3.61)$ & 0.026 \\
\hline & Gojo & 71 & $22(30.99)$ & $1.98(1.21-3.26)$ & 0.007 \\
\hline \multirow[t]{6}{*}{ Kebeles } & Ambo 01 & 73 & $1(1.37)$ & 1.00 & \\
\hline & Ambo 02 & 85 & $15(17.65)$ & $15.43(1.98-119.94)$ & 0.009 \\
\hline & Ambo 03 & 80 & $28(35.00)$ & $38.77(5.11-294.10)$ & $\leq 0.001$ \\
\hline & Bako 01 & 63 & $15(23.81)$ & $22.50(2.88-175.99)$ & 0.003 \\
\hline & Bako 02 & 66 & $25(37.88)$ & $43,90(5.74-336.03)$ & $\leq 0.001$ \\
\hline & Gojo & 71 & $22(30.99)$ & $32.33(4.22-247.77)$ & 0.001 \\
\hline \multirow[t]{2}{*}{ Sex } & Female & 103 & $23(22.33)$ & 1.00 & \\
\hline & Male & 335 & $83(24.78)$ & $1.15(0.68-1.94)$ & 0.612 \\
\hline \multirow[t]{4}{*}{ Age } & Adult & 269 & 57 (21.19) & 1.00 & \\
\hline & Juvenile & 49 & $15(30.61)$ & $1.64(0.84-3.22)$ & 0.15 \\
\hline & Adolescent & 76 & $21(27.63)$ & $1.42(0.79-2.54)$ & 0.237 \\
\hline & Geriatric & 44 & $13(29.55)$ & $1.56(0.77-3.17)$ & 0.220 \\
\hline \multirow[t]{2}{*}{ Breed } & Exotic \& cross & 77 & $16(20.78)$ & 1.00 & \\
\hline & Local & 361 & $90(24.93)$ & $1.27(0.69-2.31)$ & 0.44 \\
\hline \multirow[t]{4}{*}{ Feeding } & HH leftover & 82 & $18(21.95)$ & 1.00 & \\
\hline & Raw AP & 96 & $25(26.04)$ & $1.25(0.63-2.51)$ & 0.525 \\
\hline & Mixed & 203 & $50(24.63)$ & $1.16(0.63-2.14)$ & 0.631 \\
\hline & Cooked AP & 57 & $13(22.81)$ & $1.05(0.47-2.36)$ & 0.905 \\
\hline \multirow[t]{3}{*}{ Housing } & Indoor & 93 & $21(22.58)$ & 1.00 & \\
\hline & Outdoor & 159 & $38(23.90)$ & $1.08(0.59-1.98)$ & 0.811 \\
\hline & Mixed & 186 & $47(25.27)$ & $1.16(0.64-2.09)$ & 0.622 \\
\hline \multirow[t]{2}{*}{ Visiting Vet. clinic } & No & 385 & $95(24.68)$ & 1.00 & \\
\hline & Yes & 53 & $11(20.75)$ & $0.80(0.40-1.62)$ & 0.533 \\
\hline \multirow[t]{2}{*}{ Presence of other DA } & Yes & 184 & $41(22.28)$ & 1.00 & \\
\hline & No & 254 & $65(25.59)$ & $1.20(0.77-1.88)$ & 0.425 \\
\hline \multirow[t]{4}{*}{ Educ. of the owner } & Tertiary & 145 & $31(21.38)$ & 1.00 & \\
\hline & Illiterate & 78 & $23(29.49)$ & $1.54(0.82-2.88)$ & 0.179 \\
\hline & Primary & 105 & $27(25.71)$ & $1.27(0.71-2.30)$ & 0.423 \\
\hline & Secondary & 110 & $25(22.73)$ & $1.08(.60-1.96)$ & 0.797 \\
\hline \multirow[t]{2}{*}{ Gender of the owner } & Female & 129 & $25(19.38)$ & 1.00 & \\
\hline & Male & 309 & $81(26.21)$ & $1.48(0.89-2.45)$ & 0.129 \\
\hline
\end{tabular}

$\mathrm{CI}=$ Confidence Interval $\mathrm{OR}=$ Odds Ratio, Educ. = Education, Vet. = Veterinary, $\mathrm{AP}=$ animal products, $\mathrm{HH}=$ household, $\mathrm{DA}=$ domestic animals 
All risk factors are non-collinear $(\mathrm{r}<0.6)$ except Gote and Kebele which are collinear with each other $(\mathrm{r}=0.756)$. The variable "Kebele" was selected for further multivariable logistic regression analysis (Table 4).

Table 4. Multivariable logistic regression of $E$. coli carriage and potential to risk factors

\begin{tabular}{llcc}
\hline Variables & Categories & OR (95\% CI) & $P$-value \\
\hline Districts/Towns & Ambo & 1.00 & \\
& Bako & $31.09(4.04-239.18)$ & 0.001 \\
Kebeles & Gojo & $43.45(5.64-334.70)$ & $\leq 0.001$ \\
& Ambo 01 & 1.00 & \\
& Ambo 02 & $15.16(1.95-118.08)$ & 0.009 \\
& Bako 01 & $0.51(0.24-1.10)$ & 0.087 \\
& Gojo & - & - \\
Age & Ambo 03 & $38.08(5.01-289.68)$ & $\leq 0.001$ \\
& Adult & 1.00 & \\
& Adolescent & $1.54(0.83-2.85)$ & 0.173 \\
& Geriatric & $1.11(0.53-2.31)$ & 0.781 \\
& Juvenile & $1.51(0.74-3.07)$ & 0.256 \\
Gender of the owner & Female & 1.00 & \\
& Male & $1.41(0.83-2.40)$ & 0.205 \\
\hline
\end{tabular}

\section{Antimicrobial susceptibility}

Due to a financial limitation, out of $106 \mathrm{E}$. coli isolates obtained from this study, 43 isolates were selected using a simple random sampling technique and subjected to antimicrobial susceptibility test using the phoenix machine. Overall, $76.7 \%$ (33/43), $6.98 \%$ (3/43), $2.33 \%$ (1/43), and $14.0 \%(6 / 43)$ of the isolates were pan-susceptible, resistant to one class of antimicrobial, two class of antimicrobial and $\geq 3$ classes of antimicrobials (multidrug-resistant (MDR)), respectively. The tested isolates were $100 \%$ susceptible to 12 antimicrobials; viz. amikacin, netilmicin, ampicillin, piperacillin-tazobactam, piperacillin, cefoxitin, ciprofloxacin, levofloxacin, colistin, ertapenem, meropenem, and imipenem. The most common resistance phenotypes were recorded for cefazolin (22.73\%), aztreonam (13.95\%), ceftriaxone (13.95\%), gentamicin $(11.90 \%)$, and trimethoprim-sulfamethoxazole (6.97\%) (Table 5). 
Zewdu et al.,

Table 5. Results of antimicrobial susceptibility testing of $43 \mathrm{E}$. coli isolates from dogs of Ambo, Bako, and Gojo towns of West Shewa Zone, Oromia, Ethiopia.

\begin{tabular}{|c|c|c|c|c|c|}
\hline $\begin{array}{l}\text { Antimicrobial } \\
\text { Class }\end{array}$ & Name of Antimicrobials & $\begin{array}{l}\text { MIC or } \\
\text { Conc. }\end{array}$ & $\begin{array}{l}\text { No. Res. } \\
(\%)\end{array}$ & $\begin{array}{l}\text { No. Int. } \\
(\%)\end{array}$ & $\begin{array}{l}\text { No. Sus. } \\
(\%)\end{array}$ \\
\hline \multirow{3}{*}{ Aminoglycosides } & Amikacin & $<=4$ & $0(0.0)$ & $0(0.0)$ & $43(100)$ \\
\hline & Gentamicin & $<=1$ & $5(11.90)$ & $0(0.0)$ & $37(88.10)$ \\
\hline & Netilmicin $(n=19)$ & $<=1$ & $0(0.0)$ & $0(0.0)$ & $19(100)$ \\
\hline \multirow{7}{*}{ Beta-lactam } & Amoxicillin-Clavulanate(f) $(n=20)$ & $4 / 2$ & $1(5.0)$ & $2(10.0)$ & $17(80.0)$ \\
\hline & Ampicillin $(\mathrm{n}=19)$ & $<=2$ & $0(0.0)$ & $0(0.0)$ & $19(100)$ \\
\hline & Ampicil-Sulbactam & $<=4 / 2$ & $1(2.44)$ & $6(14.63)$ & $34(82.93)$ \\
\hline & Aztreonam & $<=1$ & $6(13.95)$ & $0(0.0)$ & $37(86.04)$ \\
\hline & Piperacillin-Tazobactam & $<=4 / 4$ & $0(0.0)$ & $0(0.0)$ & $43(100)$ \\
\hline & Ticarcillin- $(\mathrm{n}=17)$ & $32 / 2$ & $0(0.0)$ & $5(29.41)$ & $12(70.59)$ \\
\hline & Piperacillin $(\mathrm{n}=18)$ & $<=4$ & $0(0.0)$ & $0(0.0)$ & $18(100)$ \\
\hline \multirow{7}{*}{ Cephalosporins } & Cefazolin (n=22) & $<=2$ & $5(22.73)$ & $0(0.0)$ & $17(77.27)$ \\
\hline & Cefepime & $<=1$ & $0(0.0)$ & $6(13.95)$ & $37(86.04)$ \\
\hline & Cefoperazole-sulbactam(n=9) & $<=0.5 / 8$ & $0(0.0)$ & $6(66.67)$ & $3(33.3)$ \\
\hline & $\operatorname{Cefoxitin}(\mathrm{n}=22)$ & $<=4$ & $0(0.0)$ & $0(0.0)$ & $22(100)$ \\
\hline & Ceftrazidime & $<=0.5$ & $0(0.0)$ & $2(4.65)$ & $41(95.34)$ \\
\hline & Ceftriaxone & $<=0.5$ & $6(13.95)$ & $0(0.0)$ & $37(86.04)$ \\
\hline & Cefuroxime $(\mathrm{n}=21)$ & $<=2$ & $1(4.76)$ & $0(0.0)$ & $20(95.24)$ \\
\hline \multirow{2}{*}{ Quinolone } & Ciprofloxacin $(\mathrm{n}=42)$ & $<=0.125$ & $0(0.0)$ & $0(0.0)$ & $42(100.0)$ \\
\hline & Levofloxacin(n=34) & $<=1$ & $0(0.0)$ & $0(0.0)$ & $34(100.0)$ \\
\hline Polymyxin & Colistin $(n=9)$ & $<=1$ & $0(0.0)$ & $0(0.0)$ & $9(100)$ \\
\hline \multirow{2}{*}{ Carbapenem } & Ertapenem & $<=0.25$ & $0(0.0)$ & $0(0.0)$ & $43(100)$ \\
\hline & Meropenem & $<=0.125$ & $0(0.0)$ & $0(0.0)$ & $43(100)$ \\
\hline Carbapenams & Imipenem & $<=0.25$ & $0(0.0)$ & $0(0.0)$ & $43(100)$ \\
\hline Glycylcyclines & Tigecycline & $<=0.5$ & $0(0.0)$ & $2(4.65)$ & $41(95.34)$ \\
\hline FPI & Trimethoprim-Sulamethoxazole & $<=1 / 19$ & $3(6.97)$ & $0(0.0)$ & $40(93.02)$ \\
\hline
\end{tabular}

Among the antimicrobials used, multidrug-resistant (resistant to three or more antibiotics) was observed against amoxicillin-clavulanate (f), ampicillinsulbactam, aztreonam, cefazolin, cefepime, ceftriaxone, gentamicin, ticarcillin-clavulanate, ticarcillin-clavulanate, tigecycline, and trimethoprim-sulfamethoxazole. Multidrug resistance (MDR) was observed in $6 \mathrm{E}$. coli isolates $(14.0 \%, 6 / 43)$. The maximum number of antimicrobials class to which an isolate demonstrated resistance was 5 (Table 6). 
Table 6: Drug-resistant pattern of E. coli isolates from dogs in Ambo, Bako and Gojo towns of West Shewa Zone

\begin{tabular}{lc}
\hline Antimicrobials & Number of isolates (\%) \\
\hline AMC, AM & $1(2.33)$ \\
CLN, TIG & $1(2.33)$ \\
ATM, CRO, GM & $3(6.98)$ \\
ATM, CZ, CRO, GM & $1(2.33)$ \\
ATM, CXM, CRO, SXT & $1(2.33)$ \\
ATM, CZ, CRO, GM, SXT & $1(2.33)$ \\
Total & $\mathbf{8}(\mathbf{1 8 . 6 \% )}$
\end{tabular}

AMC: Amoxicillin-Clavulanate AM: Ampicillin CLN: Colistin TIG: Tigecycline CZ: Cefazolin ATM: Aztreonam CRO: Ceftriaxone CMX: Cefuroxime GM: Gentamicin SXT: Trimetho-Sulphamethoxazole.

Antimicrobial resistance did not show a statistically significant association with towns $(P>0.05)$. But, antimicrobial resistance in Ambo was higher $23.81 \%$ (5/21) when compared with Bako (21.43\%) and Gojo (12.5\%) towns (Fig.1).

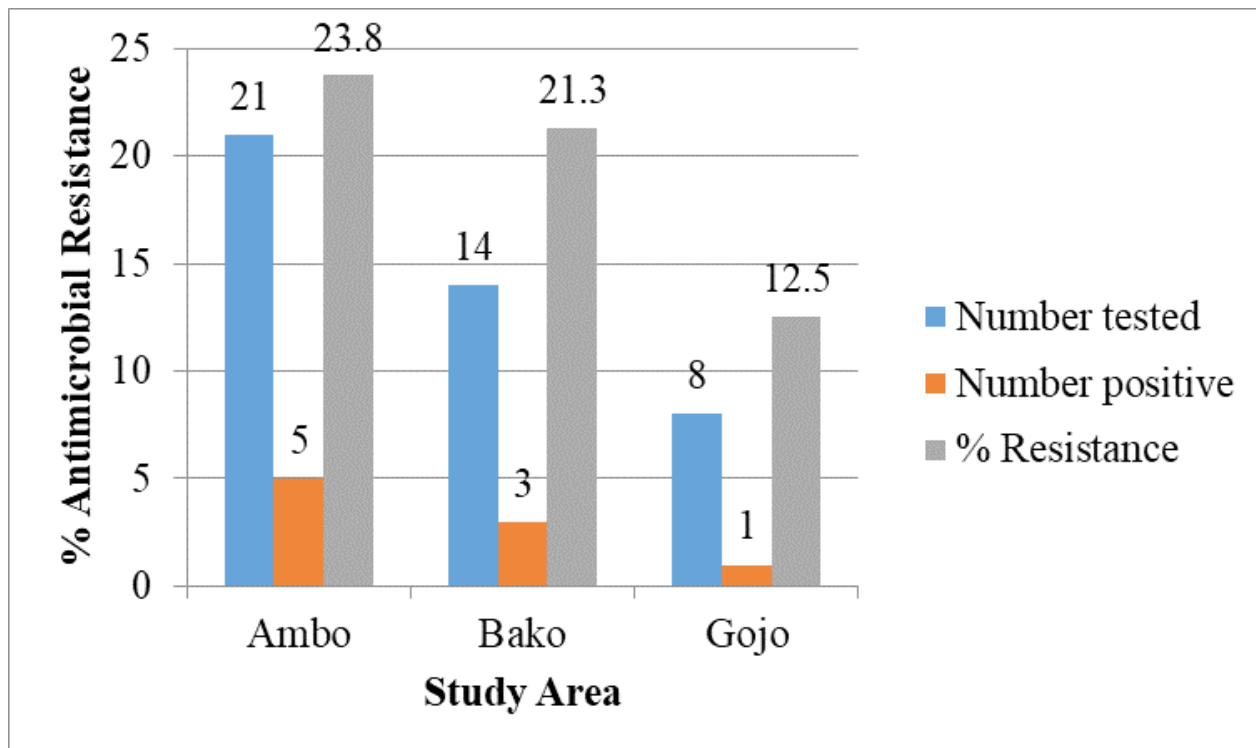

Fig 1. Distribution of antimicrobial resistant $E$. coli in the study towns 


\section{Discussion}

Although most dogs carry commensal bacteria in their gut, E. coli is one of the most common opportunistic pathogens causing enteritis or diarrhea in addition to extra-intestinal infections in animals and human (Beutin, 1999). Besides this, dogs harboring $E$. coli could serve as a reservoir of antimicrobial resistance determinants (Johnson and Russo, 2002). Antimicrobial resistance is a well-known global challenge in the management of bacterial infections. In the current study, a $24.2 \% \mathrm{E}$. coli isolation rate was obtained from rectal swab samples of apparently healthy dogs. To the best of the authors' knowledge, this is the first study on prevalence, risk factors, and antibiogram of $E$. coli isolates from dogs in Ethiopia. This finding was comparable with the $21 \%$ isolation rate of hemolytic $E$. coli from the feces of healthy bitches in Australia (Chen et al., 2003). The present finding was higher than the finding of Beutin et al., (1993) who reported a $4.8 \%$ isolation rate from healthy dogs but lower than the reports of previous studies (Hammermueller et al., 1995; Beutin, 1999; Salvadori et al., 2003) who detected approximately $59-61 \%$ isolation of $E$. coli from dogs with diarrhea. The present result is also lower than $37.14 \%$ E. coli isolation from dogs in Alexandria (Younis et al., 2015). The difference in the prevalence of $E$. coli among studies might be due to the difference in the season of the study (Rowland, 1986), age, immune status, stage of infection, number of samples analyzed (Shaheen et al., 2011; Yunis et al., 2015), sampling techniques, and health status of dogs sampled (sick/hospitalized dogs vs healthy). The other reason for the difference in prevalence among studies might be due to the volume of fecal samples collected (rectal swab vs. large volume of feces). The use of rectal swabs in the present study might have underestimated the prevalence of $E$. coli infection in dogs due to the small volume of feces used for analysis. The health status of the sampled dogs could be also another source of variation among the reports in that a higher prevalence is more likely from diarrheic dogs than apparently healthy dogs. Although cases of diarrheic dogs were not registered and quantified during the current study, it is known that $E$. coli infected dogs with diarrhea defecate frequently and uncontrollably, contaminate the environment, and spread the bacteria more than non-diarrheic dogs (Hammermueler et al., 1995; Torkan et al., 2016).

The significantly high prevalence of E. coli in dogs of Bako and Gojo towns might be related to the relatively lower hygiene of dogs, and inadequate sanitation of dogs' feeds, and dog environment. Although indoor dogs are expected to be at lower risk of $E$. coli infection than outdoor dogs, in our study no signifi- 
cant difference was observed. Perhaps, due to the raw animal product feeding as well as the poor hygienic status of homemade diets of indoor dogs similar to that of outdoor dogs. Outdoor dogs feed on contaminated feeds such as leftover feed, dead poultry, and other animals, which might serve as vehicles for $E$. coli transmission to dogs.

In the present study, several potential risk factors for the carriage of $E$. coli in the household of dogs in Ambo, Gojo, and Bako towns of West Shewa Zone were investigated. Among these risk factors, multivariable logistic regression analysis revealed that study sites (towns) and Kebeles were important predictors of E. coli infection in dogs. The reason behind the high prevalence in Gojo and Bako towns as compared to Ambo town is not well known. However, it might be due to the poor sanitary practices in the households and its surroundings, and inadequate sanitary facilities for people. Because animal feces are plentiful source of E.coli infection (Bach et al., 2002), high in dog (Gebremedhin et al., unpublished) and other livestock populations in the towns of Bako and Gojo compared to Ambo may have contributed to the high E. coli prevalence. Michel et al. (1999) also pointed out that living in an agricultural area where cattle are raised could be a significant risk factor for the acquisition of $E$. coli. Moreover, the cool and humid climatic condition of Gojo town is suitable for prolonged survival and infectivity of the bacteria. The significant difference in the prevalence of $E$. coli infection between Kebeles of the study area might be because of the variation in the number of butcher shops, restaurants and cafeterias providing $E$. coli contaminated leftover foods to dogs coupled with variation in sanitary practices including the location of the slaughterhouse that might directly or indirectly influence across Kebeles.

Antimicrobial resistance in bacteria is a phenomenon that has been in constant evolution since the introduction of antimicrobial drugs. Several factors are known to promote bacterial resistance including failure of a treatment regimen, prophylactic use of antimicrobials, and the use of antimicrobials as growth promoters as well as using antimicrobials commonly used in humans' practice (DACA, 2009). Antimicrobial resistance has been suggested as one important therapeutic problem in veterinary and human medicine (DACA, 2009). In this study, antimicrobial resistance of $E$. coli isolated from apparently healthy dogs was investigated against 25 antimicrobial drugs using the MIC technique. Overall, moderately low antimicrobial resistance was found (20.93\%). The antimicrobial susceptibility of $E$. coli isolates to multiple antimicrobials was also detected. The $E$. coli isolates were pan-susceptible to er- 
tapenem, imipenem, piperacillin-tazobactam, amikacin, netilmicin, ampicillin, cefoxitin, ciprofloxacin, levofloxacin, colistin, and meropenem. This might be due to the less availability and utilization of these drugs in the country and study area. Susceptibility of E. coli isolates to ciprofloxacin, ceftazidime, aztreonam, cefepime, ceftriaxone and gentamicin could also be attributed to their inadequate utilization in canine clinical practice in Ethiopia. The lower level of antimicrobial resistance observed against aztreonam, ceftriaxone, (13.95\% each), cefazolin (22.73\%), gentamicin (11.90\% each) and trimethoprim-sulphamethoxazole (6.97\%) in the present study is in line with the $79 \%$ antimicrobial susceptible $E$. coli isolates reported previously (Windahl et al., 2014). Unlike the present study, increased detection of pathogenic and non-pathogenic $E$. coli that are resistant to antimicrobial drugs have been previously reported (Hammermueler et al., 1995; Ewers et al., 2012).

The present findings are also in line with the study conducted by Wedley (2017) who reported the pan-susceptibility to piperacillin-tazobactam and high susceptibility to aztreonam. Dogs are generally the close companions of their human caretakers thereby providing opportunities for the exchange of antimicrobial-resistant bacteria. The MDR in the current study (14.0\%) is not greatly different from previous reports such as 15.3\% (Wedley, 2017) and 15\% (Wedley et al., 2011) MDR in healthy dogs in the UK. Relatively high prevalence of MDR $E$. coli in sick dogs (29\%) have been reported in the U.S.A (Shaheem et al., 2010). A lower level of MDR E. coli (11\%) has also been reported in healthy dogs of the U.S.A (Davis et al., 2011). This variation in the level of antimicrobial resistance could probably be attributed to the expression of resistant gene coded by the pathogen, which is associated with the emerging and re-emerging aspects of the isolates in different agro-ecology (Reubaen and Owuna, 2013). Differences in the prevalence of resistance observed might also be due to differences in the interpretation of the zone sizes, MICs observed, or differences in how intermediate measurements were classified (Wedley et al., 2017).

Low level or absence of individual antimicrobial resistance in $E$. coli isolates in the present study might be an indication of the low level or absence of antimicrobial drug usage in dogs in the study areas for prophylaxis or treatment purpose. This observed a lower level of resistance to some antimicrobial drugs might also be due to acquiring either from contaminated feed and improperly managed leftover household human foods containing AMR $E$ coli, which were normally given to dogs. Feeding of dogs with animal products containing high levels of antimicrobial residues may contribute to the emergence of antimicro- 
bial resistance in bacteria recovered from dogs (Prescott et al., 2002). Thus, it is fundamental that veterinarians' guide dog owners towards the use of treatment regimens for sick dogs and the establishment of long-term preventive programs against infectious diseases such as diseases caused by $E$. coli.

The emergence of antimicrobial resistance or MDR (14.0\%) E. coli in household dogs, though at a lower level, is of public health and economic importance in that it indicates the potential of the spread of AMR E. coli from dogs to humans and other animals. Therefore, attention should be given to the management of dogs, and the provision of safe feed and water, which might contain antimicrobial residues contributing to the source of the resistance. According to the reports of DACA (2009), antimicrobial resistance has been incriminated with higher mortality and morbidity, increased costs of treatment, and loss of productivity.

The limitations of this study is that data on dog hygiene and environmental hygiene was not captured during questionnaire survey. Besides, molecular studies aimed at determining virulence genes and pathotypes of $E$. coli was not done to determine the pathogenicity of $E$ coli isolates in the current study due to the limitation of resources and facilities. Nevertheless, isolation of $E$. coli is of great public health concern because there is close contact between dogs and humans and poor awareness and hygiene are common, as some isolates might be of zoonotic risk for humans coupled with the potential transfer of MDR genes. Although we couldn't prove the pathogenicity of the $E$. coli isolates, it could be hypothesized that dogs in the current study aeas were exposed to potentially pathogenic $E$. coli from the contaminated environment such as drinking contaminated water and feeding on dead animals, animal products and garbage.

\section{Conclusions}

The overall prevalence (24.2\%) of $E$. coli infection dogs in the study area is moderately high. Study towns and study Kebeles are the important predictors of $E$. coli infection in the study area. Most of the $E$. coli isolates from dogs are susceptible to many of the drugs used in both human and veterinary medicine. However, some of the isolates have developed multidrug resistance and might be a potential source of the spread of antimicrobial-resistant $E$. coli from dogs to humans and other animals. Further, large-scale epidemiological studies including the contribution of dogs in the transmission to humans, serotyping 
and virulence gene detection of $E$. coli, frequent monitoring of antimicrobial drug resistance and responsible dog ownership, and improved hygienic management of dogs are recommended.

\section{References}

Abdissa. R, Haile. W, Fite. A. T, Beyi. A. F, Agga. G. E, Edao. B. M, Tadesse. F, Korsa.M.G, Beyene. T, Beyene. T.J, Zutter. D.L, Cox. E. and Goddeeris. B.M., 2017. Prevalence of Escherichia coli O157: H7 in beef cattle at slaughter and beef carcasses at retail shops in Ethiopia. BMC Infect Dis, 17, 1-6.

Addis Ababa City Administration (AACA, 2004. Proclamation for the establishment of "Kifle Ketema" and "Kebele" in Addis Ababa city, Addis Ababa, Ethiopia

Atnafie. B., Paulos, D., Abera, M., Tefera, G., Hailu, D., Kasaye, S. and Amenu, K.,2017. Occurrence of Escherichia coli O157: H7 in cattle feces and contamination of carcass and various contact surfaces in abattoir and butcher shops of Hawassa, Ethiopia. BMC Microbiol.17, 24.

Bach, S.J., McAllister, T.A., Veira, D.M., Gannon, V.P.J. and Holley, R.A., 2002. Transmission and control of Escherichia coli O157: H7-a review. Can. J. Anim. Sci., 82(4),.475-490.

Bekele. T, Zewde. G, Tefera. G, Feleke. A . and Kaleab. Z., 2014. Escherichia coli O157: H7 in Raw Meat in Addis Ababa, Ethiopia: Prevalence at an Abattoir and Retailers and Antimicrobial Susceptibility. Int. J. Food Cont., 1, 1-8.

Beutin, L., Geier, D., Steinruck, H., Zimmermann, S. and Scheutz, F., 1993. Prevalence and some properties of verotoxin (Shiga-like toxin)-producing Escherichia-coli in 7 different species of healthy domestic animals. J. Clin. Microbiol., 31(9), 2483-2488.

Beutin, L., 1999. Escherichia coli as a pathogen in dogs and cats. Vet. Res., 30, 285-298.

Beyi. A. F, Fite. A. T, Tora. T, Tafese. A Genu. T, Kaba. T, Beyene. T. J, Beyene. T, Korsa. M. G, Tadesse. F, De Zutter. L, Goddeeris. B. M and Cox. E., 2017. Prevalence and antimicrobial susceptibility of Escherichia coli $\mathrm{O} 157$ in beef at butcher shops and restaurants in central Ethiopia. BMC Microbiol., 17, 49.

Bihon, A., Syoum, A. and Assefa, A., 2019. Assessment of risk factors and isolation of Staphylococcus aureus and Escherichia coli from bovine subclinical mastitic milk in and around Gondar, Northwest Ethiopia. Trop. Anim. Hlth. Prod., 51, 939-948. DOI: $10.1007 / \mathrm{s} 11250-018-1777-2$.

Blaha, T., 2012. One world-One health: the threat of emerging diseases. A European perspective. Transbound Emerg. Dis., 59(S1), 3-8. 
Caprioli, A., Busani, L., Martel, J. L. and Helmuth, R., 2000. Monitoring of antibiotic resistance in bacteria of animal origin: epidemiological and microbiological methodologies. Int. J. Antimicrob. Agents, 14 (4), 295-301.

Chapman, P.A., Siddons, C.A., Cerdan Malo, A.T. and Harkin, M.A., 2000. An evaluation of rapid methods for detecting Escherichia coli $\mathrm{O} 157$ on beef carcasses in the United Kingdom. Epidemiol. Infect.,124, 207-213.

Chen, Y. M. M., Wright, P. J., Lee, C. S. and Browning, G. F., 2003. Uropathogenic virulence factors in isolates of Escherichia coli from clinical cases of canine pyometra and feces of healthy bitches. Vet. Microbiol. 94(1), 57-69.

CLSI, 2015. Performance Standards for Antimicrobial Susceptibility Testing; TwentyFifth Informational Supplement.

Central Statistical Agency, 2005. Central Statistical Agency, Federal Democratic Republic of Ethiopia; Addis Ababa: 2005. Agricultural Sample Survey 2004/2005, Vol. 1: Area and Production of Major Crops

CSA, (Central Statistics Agency), 2003. Agricultural sample survey 2001/2. Report on area and production for major crops (private peasant holdings, Meher season) Addis Ababa, Ethiopia.

Clinical Laboratory Standards Institute M100-S20 (CLSI), 2010. Performance Standards for Antimicrobial Susceptibility Testing; Twentieth Informational Supplement. Wayne, PA: CLSI.

DACA, 2009. Antimicrobials use, resistance and containment baseline survey syntheses of findings, August 2009, Addis Ababa, Ethiopia.

Damborg, P., Nielsen, S.S. and Guardabassi, L., 2009. Escherichia coli shedding patterns in humans and dogs; insights into within- household transmission of phylotypes associated with urinary tract infections. Epidemiol. Infect. 137, 1457-1464.

Dantas-Torres, F., and Otranto, D. 2014. Dogs, cats, parasites, and humans in Brazil: opening the black box. Parasites Vectors, 7(1), 22, ttps://doi.org/10.1186/17563305-7-22.

Davis, J.A., Jackson, C.R., Fedorka-Cray, P.J., Barrett, J.B. and Brousse, J.H., 2011. Anatomical distribution and genetic relatedness of antimicrobial-resistant Escherichia coli from healthy companion animals. J. Appl. Microbiol., 110, 597-604.

Dulo. F, Feleke. A., Szonyi, B., Fries, R., Maximilian, P. O. and Grace, D., 2015. Isolation of multidrug-resistant Escherichia coli $\mathrm{O} 157$ from goats in the Somali region of Ethiopia: a cross-sectional, abattoir-based study. PLoS ONE, 10, 1-10.

Ewers, C., Bethe, A., Semmler, T., Guenther, S. and Wieler, L.H., 2012. Extendedspectrum beta-lactamase-producing and AmpC-producing Escherichia coli from livestock and companion animals, and their putative impact on public health: A global perspective. Clin. Microbiol. Infect., 18, 646-655. 
Frenzen, P. and Drake, A., 2005. Economic Cost of Illness due to Escherichia coli O157 infections in the United States. J. Food. Prot. 68, 2623-2630.

Gesese, Y., Damessa, D.L., Amare, M.M., Bahta, Y.H., Shifera, A.D., Tasew, F.S. an dGebremedhin, E.Z., 2017. Urinary pathogenic bacterial profile, antibiogram of isolates, and associated risk factors among pregnant women in Ambo town, Central Ethiopia: a cross-sectional study. Antimicrob. Resist. Infect. Control. 6,132. DOI: 10.1186/s13756-017-0289-6. eCollection 2017.

Guardabassi, L., Schwarz, S. and Lloyd, D.H., 2004. Pet animals as reservoirs of antimicrobial-resistant bacteria. J. Antimicrob. Chemother. 54, 321-332.

Hammermueller, J., Kruth, S., Prescott, J. and Gyles. C., 1995. Detection of toxin genes in Escherichia coli isolated from normal dogs and dogs with diarrhea. Can. J. Vet. Res. 59, 265-270.

Johnson, J.R. and Russo, T.A., 2002. Extraintestinal pathogenic Escherichia coli: "The other bad E. coli”. J. Lab. Clin. Med., 139, 155-162

Kiflu, B., Alemayehu, H., Abdurahaman, M., Negash, Y., Eguale, T., 2017. Salmonella serotypes and their antimicrobial susceptibility in apparently healthy dogs in Addis Ababa, Ethiopia. BMC Vet Res.,13, 134. DOI 10.1186/s12917-017- 1055-y

Hiko, A, Asrat, D. and Zewde, G., 2008. Occurrence of Escherichia coli O157: H7 in retail raw meat products in Ethiopia. J. Infect. Dev. Ctries.2, 389-393.

Magiorakos, A.-P., Srinivasan, A., Carey, R.B., Carmeli, Y., Falagas, M.E., Giske,C.G., Harbarth, S., Hindler, J.F., Kahlmeter, G., Olsson-Liljequist, B., Paterson,D.L., Rice, L.B., Stelling, J., Struelens, M.J., Vatopoulos, A., Weber, J.T., and Monnet, D.L., 2012. Multidrug-resistant, extensively drug-resistant, and pan drug-resistant bacteria: an international expert proposal for interim standard definitions for acquired resistance. Clin Microbiol Infect., 18, 268-281.

McConnell, A.R., Brown, C.M., Shoda, T.M., Stayton, L. E. and Martin, C. E., 2011. Friends with benefits: on the positive consequences of pet ownership. J. Pers. Soc. Psychol. 101, 1239-1252.

Mersha, G., Asrat, D., Zewde, B.M. and Kyule, M., 2010. Occurrence of Escherichia coli O157: H7 in feces, skin, and carcasses from sheep and goats in Ethiopia. Lett. Appl. Microbiol.,50, 71-76.

Michel, P., Wilson, J.B., Martin, S.W., Clarke, R.C., McEwen, S.A. and Gyle, C.L.,1999. Temporal and geographical distributions of reported cases of Escherichia coli O157:H7 infection in Ontario. Epidemiol. Infect., 122, 193-200.

Mutaku, I., Erku, W.and Ashenafi, M., 2005. Growth and Survival of Escherichia coli O157: H7 in fresh Tropical Fruit Juices at Ambient and Cold Temperatures, Int. J. Food Microbiol., 56,133-139. 
Puno-Sarmiento, J., Medeiros, L., Chiconi, C., Martins, F. and Pelayo, J., 2013.Detection of diarrheagenic Escherichia coli strains isolated from dogs and cats in Brazil. Vet. Microbiol., 166, 676-680.

Reuben, R. and Owuna, G., 2013. Antimicrobial resistance patterns of E. coli O157:H7 from Nigerian fermented milk samples in Nasarawa state, Nigeria. Int. J.Pharm. Sci. Invention., 2, 2319-6718.

Rowland, M.G., 1986. The Gambia and Bangladesh: the seasons and diarrhea.Dialogue Diarrhoea, Sep;(26):3.

Salvadori, M.R., Valadares, G.F., Leite, D.S., Blanco, J. and Yano, T., 2003. Virulence factors of Escherichia coli isolated from calves with diarrhea in Brazil. Brazilian J. Microbiol., 34, 230-235.

Sancak, A.A., Rutgers, H.C., Hart, C.A. and Batt, R.M., 2004. Prevalence of enteropathic Escherichia coli in dogs with acute and chronic diarrhea. Vet. Res., 154, 101-106.

Sanyal, D., Douglas, T. and Roberts, R., 1997. Salmonella infection acquired from reptilian pets. Arch. Dis. Child., 77, 345-346.

Shaheen, B. W., Boothe, D. M., Oyarzabal, O. A. and Smaha, T., 2010. Antimicrobial resistance profiles and clonal relatedness of canine and feline Escherichia coli pathogens expressing multidrug resistance in the United States. J. Vet. Intern. Med.,24, 323-330.

Taye, M., Berhanu, T., Berhanu, Y., Tamiru, F., and Terefe, D., 2013. Study on carcass contaminating Escherichia coli in apparently healthy slaughtered cattle in Haramaya University slaughterhouse with special emphasis on Escherichia coli O157: H7, Ethiopia. J. Vet. Sci. Technol. 4,132.

Thrusfield, M., 2005. Veterinary Epidemiology, $3^{\text {rd }}$ ed. Blackwell Science Ltd, UK. Pp.233-250.

Tsegaye, M., and Ashenafi, M., 2005. Fate of Escherichia coli O157: H7 during the processing and storage of Ergo and Ayib, traditional Ethiopian dairy products. Int. J. Food Microbiol., 103, 11-21.

Wedley, A.L., Maddox, T.W., Westgarth, C., Coyne, K.P. and Pinchbeck, G.L. 2011. Prevalence of antimicrobial-resistant Escherichia coli in dogs in a cross-sectionalcommunity-based study. Vet. Rec., 168, 354.

Wedley, A. L., Dawson, S., Maddox, T.W., Coyne, K.P., Pinchbeck, G.L., Clegg, P.,Nuttall, T., Kirchner, M. and Williams, N.J., 2017. Carriage of antimicrobialresistant Escherichia coli in dogs: Prevalence, associated risk factors, and molecular characteristics. Vet. Microbiol., 199, 23-30. 
Zewdu et al.,

Windahl, U., Holst, B.S., Nyman, A., Gronlund, U. and Bengtsson, B., 2014. Characterization of bacterial growth and antimicrobial susceptibility patterns in canine urinary tract infections. BMC Vet. Res., 10, 217.

Younis. K., Baddour, M. and Ibrahim, M., 2015. Detection of Diarrheagenic Escherichia Coli in Pet Animals and Its Antibiotic Resistance in Alexandria Governorate. Alex. J. Vet. Sci., 45, 113-118 